\title{
Novel Biodegradable Cast Film from Carbon Dioxide Based Copolymer and Poly(Lactic Acid)
}

\author{
Qirui Sun $^{1,2} \cdot$ Tizazu Mekonnen ${ }^{1} \cdot$ Manjusri Misra $^{1,2} \cdot$ Amar K. Mohanty $^{1,2}$
}

Published online: 4 November 2015

(c) The Author(s) 2015. This article is published with open access at Springerlink.com

\begin{abstract}
Poly(lactic acid) (PLA) and poly(propylene carbonate) (PPC) blends with different levels of chain extender were prepared and cast into films. The effect of chain extender on the mechanical, thermal and barrier properties of the films were investigated. With the inclusion of the chain extender, the compatibility and interfacial adhesion between the two polymer phases were significantly improved by a mean of forming a PLA-chain extender-PPC copolymer. Reactions between the chain extender, PLA and PPC were observed through FTIR study. SEM study also confirmed the improved compatibility and interfacial adhesion. The elongation at break of the compatibilized film with optimal amount of chain extender showed dramatic increase by up to $1940 \%$. DSC studies revealed that chain extender hindered the crystallization of the film which explained the decrease in both water and oxygen barrier when adding chain extender. PLA was found to be able to enhance both oxygen and water barrier of the blend as compared to neat PPC, while in the case of the blend with chain extender, oxygen and water barrier properties exhibited reduction at the beginning. However, when increasing chain extender concentration, these two barrier performance exhibited an upward trend. It was found that PLA/PPC blend showed much better oxygen barrier property than both parent polymers, which can be ascribed to the acceleration effect of PPC on the crystallization of PLA.
\end{abstract}

Amar K. Mohanty

mohanty@uoguelph.ca

1 Bioproducts Discovery and Development Centre, University of Guelph, Guelph, ON N1G 2W1, Canada

2 School of Engineering, University of Guelph, Guelph, ON N1G 2W1, Canada
Keywords PPC P PLA - Polymer blend · Film · Chain extender

\section{Introduction}

Recent concerns over climate change have generated great interest in reducing the emission of greenhouse gases (GHG). Carbon dioxide $\left(\mathrm{CO}_{2}\right)$, as one of the $\mathrm{GHG}$, is considered to be the biggest contributor to climate change. The contribution that triggers global warming is reported to be about $66 \%$ from $\mathrm{CO}_{2}$ [1]. In the past few decades, the rapid industrialization, population growth and the associated economic activities mainly in developing countries resulted in the emission of massive amount of $\mathrm{CO}_{2}$ to the atmosphere, causing global warming. Thus, the reduction of $\mathrm{CO}_{2}$ emission has become a major global target in recent years. In order to address this issue, great efforts are being made to capture and utilize $\mathrm{CO}_{2}$, besides reducing the emission.

One of the feasible approaches to consume $\mathrm{CO}_{2}$ in the environment is to utilize it for the production of industrial polymeric materials. Poly(propylene carbonate) (PPC) is a prominent polymer that can be synthesized through the copolymerization of $\mathrm{CO}_{2}$ and propylene oxide (PO) in the presence of catalysts. The interest of synthesizing PPC through copolymerization using $\mathrm{CO}_{2}$ as raw materials has been increasing due to the breakthrough findings by Professor Inoue in 1969 [2]. As a biodegradable and bio-based polymeric material, PPC is considered to be a good candidate to complement and replace some of the petroleumbased plastics in various applications. Additionally, its large elongation at break is useful for many applications. Numerous studies have highlighted the benefits of producing PPC in terms of helping to mitigate the $\mathrm{CO}_{2}$ 
emission while reducing the current reliance on the conventional fossil-based plastics [1, 3-5]. However, the property profile of neat PPC cannot fulfill many requirements, as it is neither typical for engineering plastics nor rubbers.

PPC presents an amorphous structure and a relatively low glass transition temperature which is within the range of human body temperature. Additionally, the inherent low stiffness and poor thermal stability also limit PPC's industrial application to a large extent. In terms of improving the properties of PPC and exploring new applications, many studies have focused on developing new processing methodologies [6-8]. Blending of two or more polymers is a well-established technique to address the material property limitations of individual polymers. In general, optimal polymer blends can provide advantage over the individual polymers in terms of processibility, material performance, and cost.

Poly(lactic acid) (PLA) is a renewable and compostable thermoplastic, with potential applications in the plastics industry. L-lactic acid, which is used to synthesize PLA, can be obtained by fermenting renewable sugar resources, such as starch and other polysaccharides through a biotechnological process involving lactobacillus bacteria. The raw materials of L-lactic acid are inexpensive and can be easily obtained. Synthesis of PLA starts with the fermentation of dextrose obtained from biomass such as corn starch [9]. A continuous condensation reaction produces pre-polymer of PLA, which has low molecular weight. Then, a mixture of lactide isomers are formed with these oligomers. After a purification process, ring-opening polymerization (ROP) produces high molecular weight PLA polymer. Lactic acid exists in two isomeric states, Dand L-enantiomers, which can be controlled during synthesis by modifying the strains of lactobacillus used.

Besides its compostability and biocompatibility, PLA has good processibility for films, injection molding parts and composite applications [10]. PLA in general has excellent mechanical properties but lacks impact strength and elongation at break. Researchers have attempted to increase the toughness of PLA with varying routes [10].

The optimal blending of PPC with PLA may result in a blend polymeric material that exhibits a favorable property profile by combining the high elongation at break of PPC and good tensile strength and modulus of PLA. Additionally, PLA has similar chemical structure as PPC, which might help to obtain better compatibility in the blend [11]. In light of this, the PLA/PPC blend system has been investigated in some studies [3,11-13]. However, results have shown that only partial miscibility exists between PLA and PPC, resulting in unfavorable properties. Certain compatibilization needs to be introduced into the blend system in order to acquire better performance.
In this study, chain extender was incorporated into the PLA/PPC blend system at different levels of concentration. Cast films were produced from the various formulated blends. Mechanical, thermal, morphological and barrier properties of the films were then investigated.

\section{Experimental Section}

\section{Materials}

Poly(propylene carbonate) (PPC) resin was obtained from Henan Tianguan Enterprise Group Co. Ltd. (China). As shown in the data sheet, the number average molecular weight of PPC is $200,000-250,000 \mathrm{~g} / \mathrm{mol}$ and the polydispersity index was 4-6 [14]. PLA was purchased from NatureWorks LLC (United States). The grade of PLA used was 3001D. An epoxy styrene acrylic oligomer multifunctional chain extender Joncryl ADR 4368-C, referred as Joncryl, was provided by BASF in flake form (Germany).

\section{Methods}

\section{Blend Preparation}

In order to determine the optimal blending composition between PPC and PLA blends, melt blending and injection molding of PLA and PPC at different weight percent PLA/ PPC ratios were conducted. For this, varying blend composition (PPC: PLA at wt\% 0:100, 30:70, 50:50, 60:40, 100:0) ratio were prepared and their mechanical properties were evaluated. Prior to blending, the neat polymers were dried in an oven at $80{ }^{\circ} \mathrm{C}$ for $12 \mathrm{~h}$ to avoid hydrolysis during thermal processing. After drying, the neat polymers and blend samples with different compositions of PLA/ PPC were processed in a DSM Xplore micro-extruder (Netherlands) equipped with a co-rotating twin screw. The melt processing parameters: extruder temperature, residence time and screw speed were set at $175{ }^{\circ} \mathrm{C}, 2 \mathrm{~min}$ and $100 \mathrm{rpm}$, respectively based on preliminary trial optimization of parameters. After extrusion, the melted materials were injection molded with a DSM Xplore microinjection molding equipment at $175{ }^{\circ} \mathrm{C}$ extrusion temperature and $40{ }^{\circ} \mathrm{C}$ mold temperature to form tensile dog bone bars in accordance with ASTM D638.

The composition selection study based on the mechanical performance of the blend with various formulations showed that PLA/PPC 40/60 blend exhibited the optimal balance of strength and ductility (shown in results and discussion section). PLA, PPC and Joncryl pellets were dried prior to blending process. Then the PLA and PPC were blended at 40/60 ratio with the addition of $0,0.2,0.5$ 
and 1.0 phr Joncryl using a Leistriz-Micro 27 extruder equipped with a co-rotating twin screw (Germany). The processing parameters were kept constant at a temperature and screw speed of $175^{\circ} \mathrm{C}$ and $100 \mathrm{rpm}$, respectively. The extruded strand was pelletized immediately into pellets. Then the prepared blend pellets were dried at $80{ }^{\circ} \mathrm{C}$ in a vacuum oven for $12 \mathrm{~h}$. Melt film casting process with the blends was performed on a film extruder, Microtruder RCP-0625, Randcastle, New Jersey, USA. The processing parameters for film making were set to a temperature of $180{ }^{\circ} \mathrm{C}$ and screw speed of $23.2 \mathrm{rpm}$, based on preliminary experimentation trials. The obtained film has thickness in the range of $0.09-0.12 \mathrm{~mm}$.

\section{Characterization}

\section{Mechanical Properties}

Tensile strength, modulus and percent elongation at break of the neat PLA, PPC and their blend samples were measured using Instron Universal Testing Machine (Instron3382, $10 \mathrm{kN}$ load cell) with a strain rate of $5 \mathrm{~mm} / \mathrm{min}$ according to ASTM D638 method. For all the reported results, at least five dog bone injection molded specimens for every formulation were measured and the averages and standard deviations of the values were reported.

As for the PLA/PPC/Joncryl blend film specimens, the ASTM D882 method was followed to perform the tensile testing. Specimens were cut into strips from the extruded films. The method employed in this study is different from previous base line study as the ASTM D882 is specifically designed for film testing. The dimension of the specimen strips were $0.09-0.11 \mathrm{~mm}$ in thickness, $9.90-10.00 \mathrm{~mm}$ in width and $150 \mathrm{~mm}$ in length. The initial distance between the two grips of the Instron was set to be $100 \mathrm{~mm}$ according to the ASTM D882. The cross-head speed was then set to $25 \mathrm{~mm} / \mathrm{min}$. Also, at least five specimens were tested for each formulation and the averages and standard deviations were reported.

\section{Scanning Electron Microscopy (SEM)}

PLA/PPC/Joncryl blend films were cryo-fractured in liquid nitrogen. The morphologies of the fracture surface of the films were examined using a HITACHI S-570 (Tokyo, Japan) scanning electron microscope (SEM) under an acceleration voltage of $10 \mathrm{kV}$. Before examining the films, a layer of gold particles with thickness of $20 \mathrm{~nm}$ was coated on the surface of the films to enhance the electron conductivity of the sample while reducing the chances of heat accumulation on the surface of the sample, which will possibly lead to deformation of the film surface.

\section{Differential Scanning Calorimetry (DSC)}

A thermal analysis TA instrument, DSC Q-200 was used to perform the DSC analysis in nitrogen atmosphere. For every specimen, the mass was accurately measured between 5 and $10 \mathrm{mg}$. An aluminum pan was used to hold the specimens and was loaded onto the instrument. Specimens were scanned from room temperature to $200{ }^{\circ} \mathrm{C}$ with a heating rate of $10^{\circ} \mathrm{C} / \mathrm{min}$. When the temperature reached $200{ }^{\circ} \mathrm{C}$, the specimen was cooled down from 200 to $-40{ }^{\circ} \mathrm{C}$ with a cooling rate of $5{ }^{\circ} \mathrm{C} / \mathrm{min}$. Then, a second heating scan was performed on the specimens from -40 to $200{ }^{\circ} \mathrm{C}$ with the heating rate of $10{ }^{\circ} \mathrm{C} / \mathrm{min}$. The first cooling cycle was used to analyze the melt crystallization behavior of the specimens and the second heating cycle was used to investigate the glass transition temperature (Tg) and melting temperatures of the specimens.

\section{Fourier Transform Infrared Spectroscopy (FTIR)}

The infrared (IR) spectra of PLA, PPC, Joncryl and the blend films were analyzed using FTIR spectrophotometer (Thermo Scientific Nicolet, 6700 ATR-FTIR) at room temperature with a $4 \mathrm{~cm}^{-1}$ resolution and 100 scans for each sample. The measurements between 4000 and $400 \mathrm{~cm}^{-1}$ were recorded.

\section{Thermogravimetric Analysis (TGA)}

TGA analysis was performed on the specimens by using a TA Instrument Q500 with a flow rate of $60 \mathrm{ml} / \mathrm{min}$ nitrogen. The specimens were heated up from $26^{\circ} \mathrm{C}$ (room temperature) to $450{ }^{\circ} \mathrm{C}$ at a rate of $20^{\circ} \mathrm{C} / \mathrm{min}$. The temperature where the maximum degradation rate occurred was detected with derivative thermogram (DTG).

\section{Water Vapor Transmission Rate (WVTR) Measurement}

WVTR values were determined on a Permatran- $\mathrm{W}^{\circledR}$ Model $3 / 33$ (USA, MOCON). All the Films were placed between two aluminum foil masks with a test area of $5 \mathrm{~cm}^{2}$ followed by sealing of the two foil masks with vacuum grease. After masking the film sample with aluminum foils, the sample was placed in a test cell and was clamped between two chambers. Nitrogen flow rate was set to 100 SCCM (standard cubic centimeter per minute) for cell. Prior to starting the test, a 2-h conditioning process, which only uses dried nitrogen to flush the entire system to clear out any existing water vapor was performed for each test cell. All the tests were then carried out according to ASTM F1249 standard. As per this standard, the test condition was at a temperature of $37.82 \pm 0.1{ }^{\circ} \mathrm{C}$ and a relative humidity 
of $100 \%$. With the water vapor permeating through the samples, the $\mathrm{N}_{2}$ (carrier gas) takes the water vapor to the sensor of the equipment and the WVTR were recorded continually. For every test, it typically took 8-12 h to reach a steady state. At least four experiments were repeated for each film formulation. The average value and standard deviation were reported.

\section{Oxygen Transmission Rate (OTR) Measurement}

OTR values were determined on an Oxtran- $\mathrm{W}^{\circledR}$ Model 2/21 (USA, MOCON). Films were also masked with aluminum foils and clamped onto the two test cells. The equipment was connected to an oxygen and a nitrogen/ hydrogen (with a $98 \%$ nitrogen and $2 \%$ hydrogen) cylinders. Oxygen flow rate was set to 20 SCCM and nitrogen/hydrogen flow was set to 10 SCCM. Prior to the start of the test, a 2-h conditioning and individual zero process were applied. All the tests were performed according to ASTM F3985 standard. In accordance with this standard, the test condition was set at a temperature of $23 \pm 0.1^{\circ} \mathrm{C}$ and a relative humidity of $0 \%$. Oxygen concentration of $100 \%$ was used. With the oxygen permeating through the samples, the $\mathrm{N}_{2} / \mathrm{H}_{2}$ (carrier gas) takes the oxygen to the sensor of the equipment and the OTR was recorded continually. For every test, it typically took 12-30 $\mathrm{h}$ for the individual zero process and 10-12 $\mathrm{h}$ for the actual test to reach a steady state. At least three experiments were repeated for each film formulation. The average value and standard deviation were reported.

\section{Statistical Analysis}

The results obtained from mechanical properties tests, oxygen transmission rate tests and water vapor transmission rate tests were statistically analyzed using the ANOVA one-way variance analysis procedure on the Minitab Ver. 16 (Minitab Inc., State College, PA). A significance of 0.05 for all the analysis was used. The means and standard deviations were analyzed and compared with the Tukey pairwise comparison test.

\section{Results and Discussion}

\section{Mechanical Properties}

Mechanical property testing of injection molded PLA/PPC blends was performed to determine the optimum blend composition for further processing and development of the blend based films. As such, blends with 70PLA/30PPC, 50PLA/50PPC and 40PLA/60PPC were prepared and tested. Stress-strain curves of injection molded PLA/PPC blend samples tested at $5 \mathrm{~mm} / \mathrm{min}$ are displayed in Fig. 1 . It was observed that neat PLA showed high tensile yield strength with very low elongation at break. Samples failed without necking at a strain of around $5 \%$. On the other hand, the neat PPC exhibited higher elongation with apparent long necking, indicating that the inherent brittleness of PLA could be modified by blending with PPC [12]. Elongation at break values for PPC tested at $5 \mathrm{~mm} / \mathrm{min}$ could not be achieved as the value exceeds the limits of the testing machine. At a testing speed of $50 \mathrm{~mm} / \mathrm{min}, \mathrm{PPC}$ has an elongation at break value of $145 \pm 17 \%$; however this cannot be used in direct comparison with other formulations as tensile properties are quite sensitive to the testing speed adopted. As for the PLA/PPC blends, it was noted that the elongation at break of the blend showed significant increment while the tensile strength at yield was constantly decreasing with the increase in PPC. The 40PLA/60PPC blend showed a significant increment in the elongation at break with slight decrease from 52 to $48 \mathrm{MPa}$ in tensile yield strength as compared to the 50PLA/50PPC blend. It can be noted that PLA/PPC with 40/60 formulation presented balanced stiffness while giving a large rise to the elongation, which makes it an optimal formulation for PLA/PPC blend in terms of increasing ductility without losing much strength. Additionally, limited processing temperature window is expected with higher content of PPC in the blend because of relatively poor thermal stability of PPC. As such, the mechanical property testing of the blend exhibited that 40PLA/60PPC blend could be considered as the optimal composition for film development taking into account the tensile strength and elongation.

Figure 2 illustrates stress-strain curves of 40PLA/ 60PPC blend films with different levels of Joncryl: $0,0.2$, 0.5 and 1 phr. For all films, three main regions were discernible: elastic deformation, yielding, and stress hardening. It is noted that for the PLA/PPC blend without Joncryl, the elastic deformation region ended quickly as strain increased, but this region was extended significantly with the inclusion of Joncryl into the blend. This extension revealed large increment in the strength of the films, providing promise to reversible deformation of the films under certain load. The curve showed significant yielding region followed by intense stress hardening for all films. With more Joncryl in the blend, the area of stress hardening region was expanded, indicating increased elongation at break. However, when Joncryl reached 1 phr in the blend, the stress hardening region ended at much lower stain rate than that of blend with $0.5 \mathrm{phr}$ Joncryl.

As shown in Fig. 3a and b, increasing Joncryl content from 0.2 to $1 \mathrm{phr}$ in the PLA/PPC blend films resulted in higher tensile strength and secant modulus values as compared with PLA/PPC blend films without Joncryl. Also, the 
Fig. 1 Stress-strain curves of PLA and PLA/PPC injection molded blends
Fig. 2 Stress-strain curves of PLA/PPC blend films with and without Joncryl
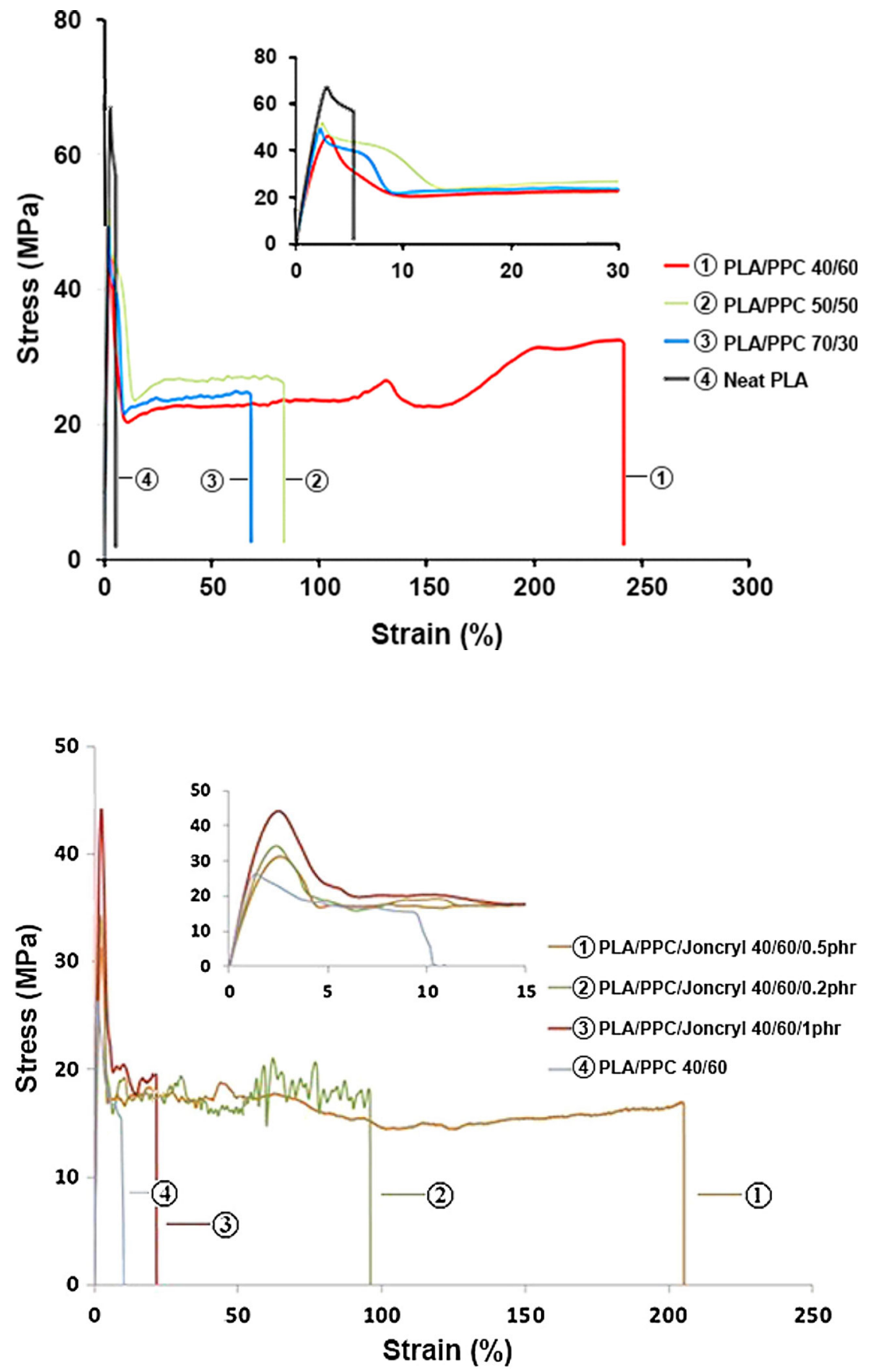

elongation at break of the films was significantly enhanced with the loading of Joncryl. Specifically, at 0.2 phr Joncryl content, the films showed a $30 \%$ increment in tensile yield strength and $22 \%$ in secant modulus while the elongation at break was enhanced by $935 \%$. The films with $0.5 \mathrm{phr}$ Joncryl exhibited a $37 \%$ increment in both tensile strength and a $16 \%$ in secant modulus, along with a huge increase (by $1940 \%$ ) in the elongation at break as compared to the film without Joncryl. Interestingly, as for the films with $1 \mathrm{phr}$ Joncryl, the tensile strength and secant modulus showed a $40 \%$ and $23 \%$ increase as compared with the pure blend, but the elongation at break did not display any significant difference according to the statistical analysis. The lower elongation at break of film with 1 phr Joncryl as compared with 0.2 and 0.5 phr Joncryl samples could be related to the occurrences of more cross-linkings between the polymer chains when loading more Joncryl into the blend system [15]. Moreover, it was suggested that the incorporation of Joncryl does not only extend the polymer chains but also able to result in forming a long chain 
Fig. 3 Tensile Strength at yield with secant modulus (a) and Elongation at break (b) of PLA/ PPC blend films with and without Joncryl: $A$ PLA/PPC (40/60) blend films, $B$ PLA/ PPC/Joncryl (40/60/0.2 phr) blend films, $C$ PLA/PPC/Joncryl (40/60/0.5 phr) blend films, $D$ PLA/PPC/Joncryl (40/60/ $1 \mathrm{phr})$ blend films
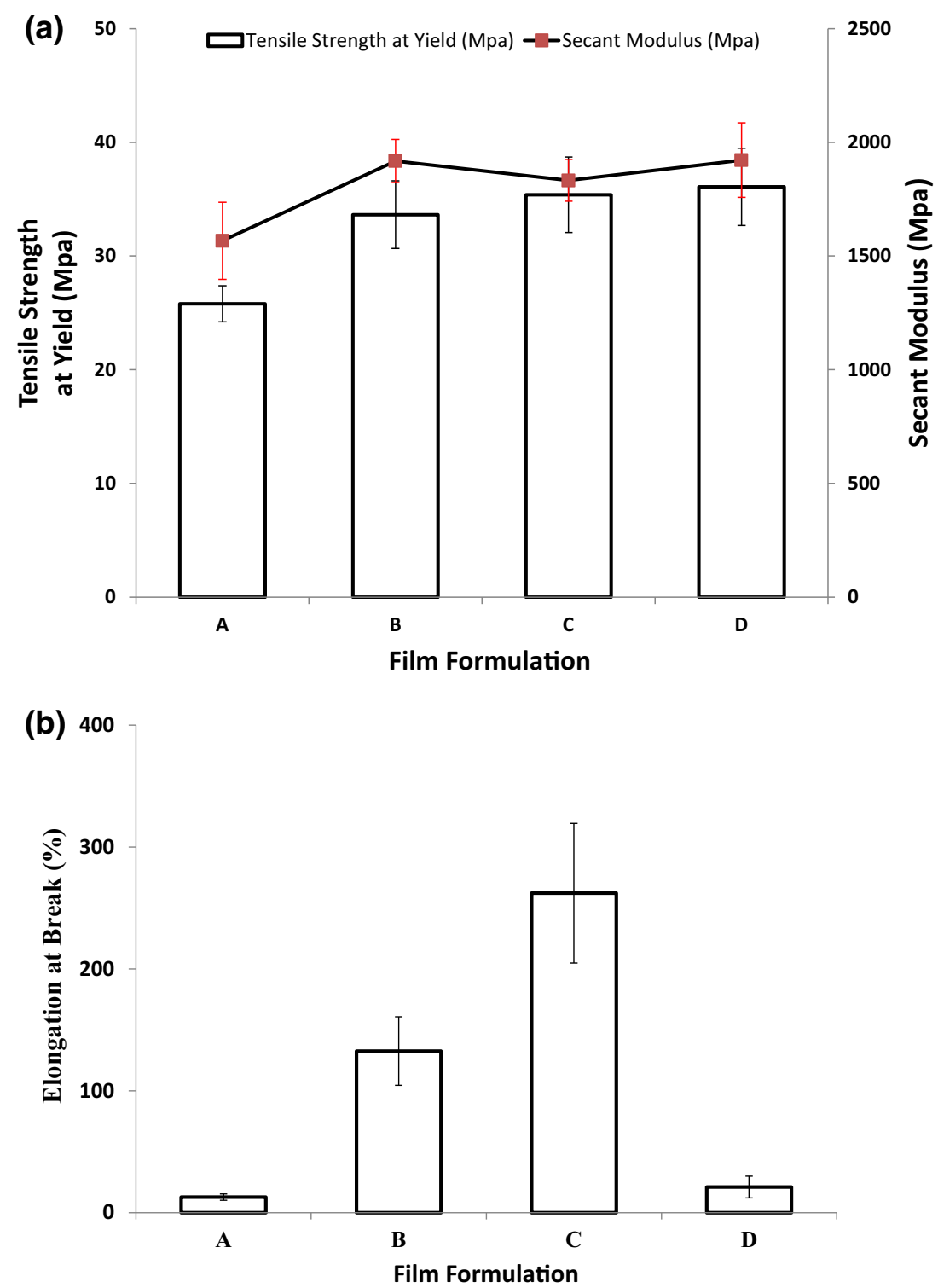

branched structure [16]. With higher concentration of Joncryl in the blend, there is a higher probability of more frequent cross-linking by joining chain ends with functional groups. In the presence of more cross-linking and long chain branching structures, the mobility of the polymer chain in the blend system is expected to decrease significantly. Thus, during the strain hardening period, it would be difficult for the polymer chains to move and rearrange, resulting in low elongation at break. Similar observation was reported in the study conducted by Khonakdar et al. [17]. In their case, with more inclusion of chain extender in HDPE, increased cross-linking between the polymer chains imposed more restriction on the elongation behavior of the polymer, resulting significant decrease in elongation at break. Another possible reason for the drastic decrease in the elongation for film with $1 \mathrm{phr}$ Joncryl might be that the occurrence of stress concen- trations induced by the chain extended PLA as a minor phase in the blend. The stress concentrations can be responsible for the reduction in the ductility of the film with 1 phr Joncryl. Similar observation has been observed by other researchers when the PLA is the minor component (40 wt \%) in the blend, chain extended PLA dispersed phase acted as stress concentrators in the presence of Joncryl. As a result the elongation at break was drastically decreased [15]. The improvement in tensile strength and secant modulus of the films could mainly be due to the formation of higher molecular weight, longer chain structure and cross linking. There were some increase in the strength and modulus with the addition of $0.2 \mathrm{phr}$ into the blend. However, no significant difference in the strength and modulus was observed when increasing the concentration of Joncryl to $0.5 \mathrm{phr}$ and $1 \mathrm{phr}$ according to the statistical analysis. This is attributed to the small amount of 
Joncryl in the blend system, which was not efficient enough to enhance the strength and modulus to a large extent. This has also been confirmed in other studies [15, 18]. The increased elongation at break can be ascribed to the improved compatibility obtained from the formation of PLA-Joncryl-PPC copolymer. Since PPC and PLA both have carboxyl functional end groups on their chains, the Joncryl has the potential to react with both PLA and PPC, forming a copolymer. The formation of PLA-Joncryl-PPC copolymer can greatly reduce the interfacial tension while increasing the interfacial adhesion, resulting in much better compatibility. The compatibilization function of Joncryl has been confirmed in several studies. It was reported in one study that the incorporation of Joncryl could increase the compatibility of the blend system through the formation of intensive ester linkages between the PLA/PBAT polymer chains [19]. Another study also proposed the formation of copolymer PLA-Joncryl-PBAT with the compatibilization of Joncryl [15]. As such, the compatibility of PLA/ PPC blend system in the films has been improved by the addition of Joncryl due to the formation of copolymer between the PLA/PPC polymer chains and Joncryl chains, providing improvement in interfacial adhesion between phases. The ductility of the matrix (PPC) with improved compatibility with PLA promises the observed high elongation at break of the films. The blend film with $0.5 \mathrm{phr}$ Joncryl exhibited best performance with largely improved elongation at break along with slightly enhanced strength and modulus compared to other formulations.

\section{Differential Scanning Calorimetry (DSC)}

Non-isothermal differential scanning calorimetry (DSC) analysis was conducted on the film specimens to investigate the thermal properties of the PLA/PPC films with and without Joncryl. With the aim to investigate the crystallization behavior of the PLA/PPC and PLA/PPC/Joncryl films, it is important to compare the degree of crystallinity of these film samples. As such, the degree of crystallinity of the PLA components (Xc, PLA) for all the film samples was calculated under the assumption that PLA is the only crystal phase present in the films. The $X \mathrm{c}$, PLA was obtained by using the following equation

$X \mathrm{c}$, PLA $=\frac{\left(\Delta H_{m}, P L A-\Delta H_{c c}, P L A\right)}{\Delta H_{m}^{0}, P L A \times W_{f} P L A} \times 100$

where the $\Delta H_{m}, P L A$ is the heat of melting of the PLA crystal. The $\Delta H_{c c}, P L A$ is the heat of cold crystallization of the PLA components in different films. As no cold crystallization was observed, $\Delta H_{c c}, P L A$ was zero in this study. The $\Delta H_{m}^{0}, P L A$ is the theoretical heat of melting of a $100 \%$ crystalline PLA, which is reported as $93 \mathrm{~J} / \mathrm{g}$ [15]. The
$W_{f} P L A$ is the weight fraction of PLA component in all the films. All the DSC parameters obtained from the cooling and heating scan of PLA/PPC and PLA/PPC/Joncryl films were listed in Table 1.

Single exothermic peak was observed for all films during the cooling cycle, which can be attributed to the melt crystallization of PLA component as PPC presents a solely amorphous structure. The melt crystallization temperatures of the films have shifted to lower values from 111 to $107{ }^{\circ} \mathrm{C}$ with an increase of Joncryl concentration. This can be ascribed to the adverse effect of Joncryl on the crystallization of the films. It was suggested that the melt crystallization temperature was an indirect signal that indicated the crystallization rate and crystallinity, and a lower crystallization temperature always represents a lower crystallization rate as well as lower crystallinity [20]. This is again proved by the reducing heat of melt crystallization of PLA component in the film $(\Delta \mathrm{Hmc})$ along with increasing Joncryl content as summarized in Table 1 . The decreased crystallization temperature, rate and crystallinity can be caused by the formation of long molecular chains and branched structures in the polymer blend. Study showed that the addition of Joncryl could connect short chain polymer ends with its multiple functional groups to form longer chains and also could branch multiple molecule chains to form branched structure [15, 21]. In light of this, the presence of long chains and branched structure may reduce the mobility of the chains structure resulting in hindering the chain packing during the crystallization of PLA component in the blend.

A single glass transition temperature was observed for these 4 types of blend films. PPC has a Tg value of around $30-40{ }^{\circ} \mathrm{C}$ and PLA owns a $\mathrm{Tg}$ value of around $55-60{ }^{\circ} \mathrm{C}$ [3]. The difference between the Tg values of PLA and PPC is around $10-15^{\circ} \mathrm{C}$. It was mentioned in one study [11] that when blending PLA with PPC, the two individual glass transition temperatures corresponding to the two parent polymers had a tendency to move towards each other, approaching the intermediate value. The occurrence of appreciable component $\mathrm{Tg}$ value convergence was considered as a strong evidence that there is partial miscibility between the two parent polymers. Based on the results obtained from these studies, it can be suggested that the component $\mathrm{Tg}$ convergence took place in our PLA/PPC/ Joncryl blend films. Hence, the nature of neighboring $\mathrm{Tg}$ values of PLA and PPC together with the possibility of Tg convergence in the blend could explain the probability of overlapping and single $\mathrm{Tg}$ as observed in this work. The Tg of the blend slightly shifted to lower values from 39.8 to $35.0{ }^{\circ} \mathrm{C}$ with the addition of Joncryl in the blend system. This may be attributed to the reduced crystallinity of the PLA component in the blend induced by the incorporation of Joncryl as lower crystallinity leaves more amorphous 
Table 1 DSC parameters obtained from the DSC scan curves for PLA/PPC blend films with and without Joncry

\begin{tabular}{|c|c|c|c|c|c|c|}
\hline $\begin{array}{l}\text { Joncryl content }(\mathrm{phr}) \text { in PLA/PPC } \\
(40 / 60) \text { blend }\end{array}$ & $\begin{array}{l}\text { Melt crystallization } \\
\text { temperature }\left({ }^{\circ} \mathrm{C}\right)\end{array}$ & $\begin{array}{l}\Delta \mathrm{Hmc} \\
(\mathrm{J} / \mathrm{g})\end{array}$ & $\begin{array}{l}\mathrm{Tg} \\
\left({ }^{\circ} \mathrm{C}\right)\end{array}$ & $\begin{array}{l}\text { First melting } \\
\text { temperature }\left({ }^{\circ} \mathrm{C}\right)\end{array}$ & $\begin{array}{l}\text { Second Melting } \\
\text { temperature }\left({ }^{\circ} \mathrm{C}\right)\end{array}$ & $\begin{array}{l}\Delta \mathrm{Hm} 1 \\
(\mathrm{~J} / \mathrm{g})\end{array}$ \\
\hline 1 & 107.0 & 12.51 & 35.0 & 157.1 & 165.5 & 2.08 \\
\hline 0.5 & 108.4 & 13.43 & 37.5 & 158.3 & 166.6 & 2.27 \\
\hline 0.2 & 109.5 & 14.26 & 34.9 & 159.6 & 168.0 & 3.12 \\
\hline 0 & 111.0 & 15.59 & 39.8 & 161.0 & 169.8 & 5.01 \\
\hline Neat PLA & N/A & N/A & 60.1 & 0 & 168.7 & 0 \\
\hline Neat PPC & N/A & N/A & 31 & N/A & N/A & N/A \\
\hline \multicolumn{2}{|c|}{ Joncryl content (phr) in PLA/PPC (40/60) blend } & \multicolumn{2}{|c|}{$\Delta \mathrm{Hm} 2(\mathrm{~J} / \mathrm{g})$} & \multicolumn{2}{|r|}{$\Delta \mathrm{H}_{\mathrm{C}}(\mathrm{J} / \mathrm{g})$} & $\mathrm{Xc}(\%)$ \\
\hline 1 & & \multicolumn{2}{|c|}{6.34} & \multicolumn{2}{|r|}{0} & 23 \\
\hline 0.5 & & \multicolumn{2}{|c|}{7.93} & \multicolumn{2}{|r|}{0} & 27 \\
\hline 0.2 & & \multicolumn{2}{|c|}{8.73} & \multicolumn{2}{|r|}{0} & 32 \\
\hline 0 & & \multicolumn{2}{|c|}{10.98} & \multicolumn{2}{|r|}{0} & 43 \\
\hline Neat PLA & & \multicolumn{2}{|c|}{31.63} & \multicolumn{2}{|r|}{25.14} & 7.0 \\
\hline Neat PPC & & \multicolumn{2}{|c|}{ N/A } & \multicolumn{2}{|r|}{ N/A } & N/A \\
\hline
\end{tabular}

fraction volume to the molecule chains. As such, higher chain mobility decreased the glass transition temperature. As the content of Joncryl in the blend increased, there was no significant variation in the Tg of the PLA/PPC/Joncryl blend films. The reason for this could be that the occurrences of long chain branching structures and cross-linking structures limited the mobility of the molecule chains [15].

It was noted in Table 1 that PLA/PPC blend exhibited much higher crystallinity than neat PLA. This could be caused by an accelerated influence of PPC on the crystallization rate of PLA in the blend system. It was also observed in another study that PPC induced faster growth rate of the PLA spherulites, leading to accelerated crystallization rate of PLA [13].

All blend films displayed two melting temperature peaks between 160 and $170{ }^{\circ} \mathrm{C}$. The first melting peak was considered to be caused by the melt re-crystallization of the polymers, specifically the PLA component. The re-crystallization occurred during the heating cycle while the less perfect PLA crystalline structure gained enough time to melt and produce more PLA crystals. This endothermic process was correlated to the first melting peak on the curves [22]. After the re-crystallization, the more perfect PLA crystals which consisted of both the original crystals and crystals produced from re-crystallization were melted during the second melting peak. It could be observed that both melting peaks shifted to lower values with more introduction of Joncryl in the blend system. Since Joncryl have an effect on interrupting the molecular chain packing, the crystallization of perfect PLA crystals was hindered. Therefore, with the addition of Joncryl, the overall crystallization behavior of PLA was interrupted and hindered resulting in a decrease of melting temperature of the polymer blends. In addition, the crystallinity kept in a downward trend consistently along with the increasing concentration of the Joncryl, which is another evidence that Joncryl has an adverse impact on the crystallization of PLA in the blend. Different from other chain extenders, Joncryl tends to form long chain branched and cross-linking structure with polymers instead of forming long chain linear structure as other chain extenders do. The presence of these two structures highly restrains the mobility of the molecular chains, which makes the packing of chains a slow and difficult procedure. This has also been observed by many researchers when applying Joncryl into the polymer system [19, 21].

\section{Thermogravimetric Analysis (TGA)}

TGA analysis was performed on the neat PLA/PPC blend films, and films with the incorporation of $0.2,0.5,1 \mathrm{phr}$ Joncryl to investigate the effect of Joncryl on the thermal stability of the films. The onset degradation temperature for all the blends ranged between 272 and $279{ }^{\circ} \mathrm{C}$, with the $5 \%$ weight loss temperature occurred between 255 and $260{ }^{\circ} \mathrm{C}$. No significant variation in the TGA curves between the four blends was observed, illustrating that the addition of Joncryl did not affect the thermal degradation behavior of the PLA/PPC blends (results now shown here).

\section{Fracture Surface Morphology Analysis (SEM)}

The morphological structure of PLA/PPC 40/60 blend films without and with the incorporation of Joncryl, were examined via Scanning Electron Microscopy (SEM), and results are shown in Fig. 4. 
The SEM images of PLA/PPC blend film without Joncryl shows smooth fracture surface, indicating its relatively brittle fracture behavior. Elongated phase can be seen in the images but only in a few amounts. As the concentration of Joncryl continued to increase from 0 to $0.5 \mathrm{phr}$, it was observed that the fracture surface became rougher and rougher, illustrating more occurrences of ductile fracture behaviors. In addition, increasing amount of elongated phase was observed. This transformation from brittle fracture to ductile fracture demonstrated better interfacial adhesion and less tension between the two polymer phases, indicating better compatibility. The improved compatibility was caused by the formation of PLA-Joncryl-PPC copolymer through cross- linking reactions between PLA, Joncryl and PPC component in the blend, which was also seen in the FTIR study. However, when the concentration of Joncryl was increased to $1 \mathrm{phr}$, the fracture surface became smoother. This signifies that a transition from ductile fracture to brittle fracture occurred, which can be correlated to the increasing density of long chain branching and cross-linking structures which restrained the elongation behavior of the blend. The observation from SEM were in agreement with observations from the mechanical properties, where films with 0.5 phr Joncryl exhibited enormous increase in elongation at break, whereas, drastic decrease in elongation at break was obtained for the films formulated with 1 phr Joncryl.
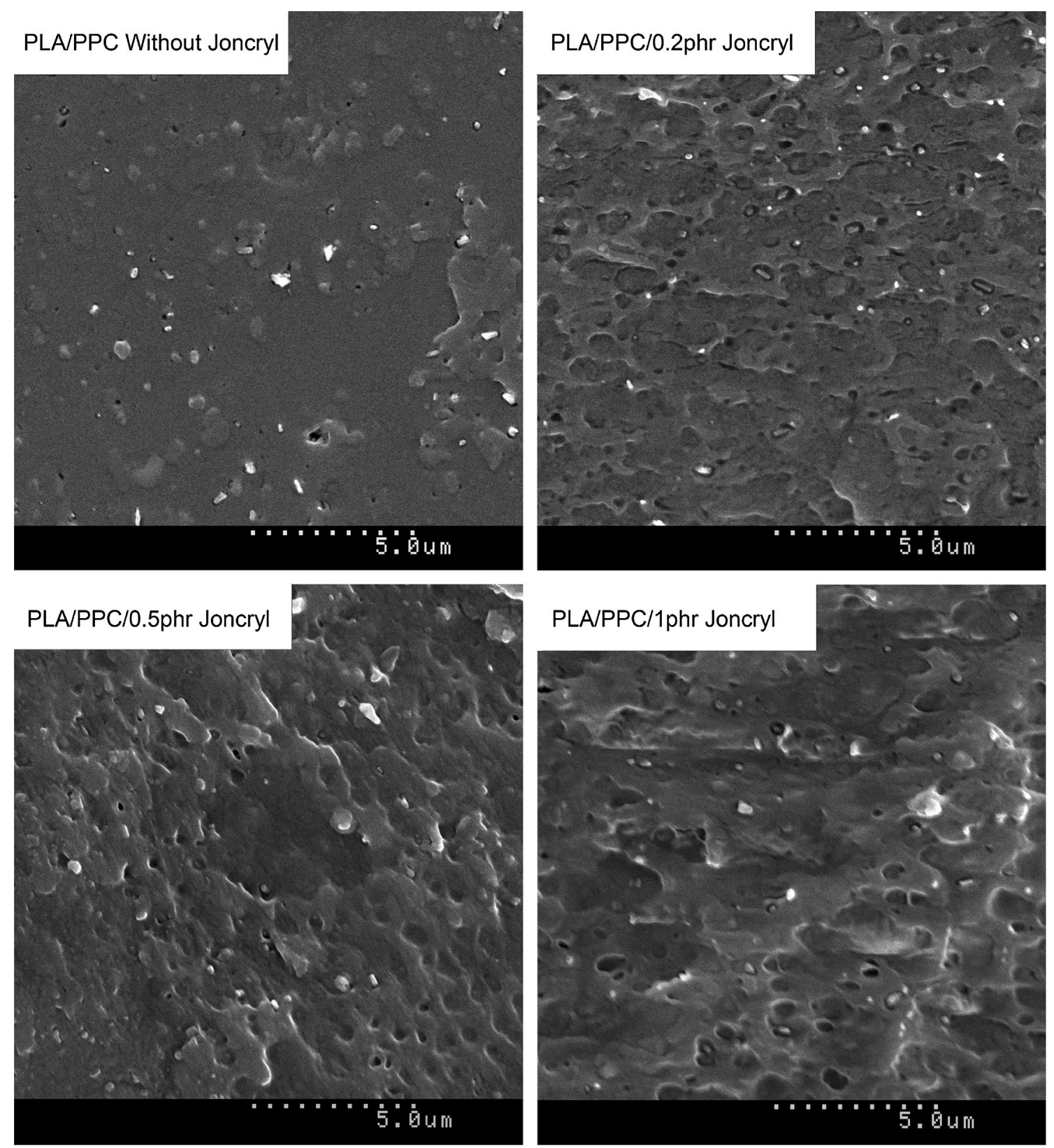

Fig. 4 SEM micrographs of the surfaces of the cryo-fractured PLA/PPC blend films with and without Joncryl 


\section{Fourier Transform Infrared Spectroscopy (FTIR)}

With the intention to investigate the interactions between PLA, PPC and Joncryl in the blend film, FTIR spectra of PPC, PLA, Joncryl, and PLA/PPC 40/60 blend film with and without Joncryl were collected. Since no apparent differences were observed between the IR spectra for PLA/ PPC blend films with different concentration of Joncryl, a typical PLA/PPC blend film with $0.5 \mathrm{phr}$ Joncryl was selected as representative sample in this research work for FTIR analysis.

Figure 5 shows the FTIR spectra of neat polymers and their blend films. In the $1700-1800 \mathrm{~cm}^{-1}$ region, the spectra of both PLA and PPC showed a strong carbonyl stretching. The peak of the carbonyl group in PLA/PPC blend was at the frequency that falls in between the frequency of carbonyl group of PLA and PPC, which gave a strong evidence that there was appreciable chemical interaction occurring between the two polymers [23]. An extensive investigations on poly(vinyl phenol)/PCL blends exhibited similar carbonyl absorption peak shift [24]. Another study suggested that the formation of a strong chemical interaction between the parent polymers could increase the stretching absorbance frequency of carbonyl $\mathrm{C}=\mathrm{O}$ group while initiating a shift to higher or lower frequency [12]. In light of this observation, it could be concluded that strong chemical interaction related to carbonyl groups took part in the PLAPPC blend system. Another possibility is that a chemical reaction occurring between PPC and PLA that could result in co-polymer chains through ester-ester interchange reactions. As for PLA/PPC blend film and the typical blend film with $0.5 \mathrm{phr}$ Joncryl in the $1800-1700 \mathrm{~cm}^{-1}$ region, the stretching peak of Joncryl-compatibilized film (e) exhibited slight shift towards lower wavenumber compared with the neat blend (c). This could be ascribed to the reaction between the functional groups of Joncryl and end groups of PLA/PPC blend.

Absorbance peak at $1223 \mathrm{~cm}^{-1}$ could be correlated with the $-\mathrm{C}-\mathrm{O}-\mathrm{C}-$ groups in the PPC [25]. With the addition of PLA, it could be observed that the $-\mathrm{C}-\mathrm{O}-\mathrm{C}-$ stretching vibration peak shifted to lower wavenumbers for the PLA/ PPC blend. This is another indication of chemical interaction that took place at the $-\mathrm{C}-\mathrm{O}-\mathrm{C}-$ bond or around the $\mathrm{C}-\mathrm{O}-\mathrm{C}$ bond through the blending of the two polymers.

The vibration peak appeared around 1180, 910, 850 and $760 \mathrm{~cm}^{-1}$ in the Joncryl spectra is attributed to the stretching peak of $\mathrm{CH}_{2}-\mathrm{O}-\mathrm{CH}$ epoxy groups [19, 25-27]. After blending Joncryl with the PLA/PPC blend, the stretching peak of epoxy groups in Joncryl almost disappeared, indicating that the epoxy groups were consumed as a result of the chemical reactions with the two polymers in the blend system. Epoxy functional groups, being very reactive at high temperature, can trigger the formation of carbonyl-hydroxyl covalent bond within the polyesters [28], providing the possibility of forming PLA-JoncrylPPC copolymer as stated above. The aforementioned observation of carboxyl functional groups shifts of $\mathrm{C}=\mathrm{O}$ peaks in PLA/PPC blend is also possible in line with the

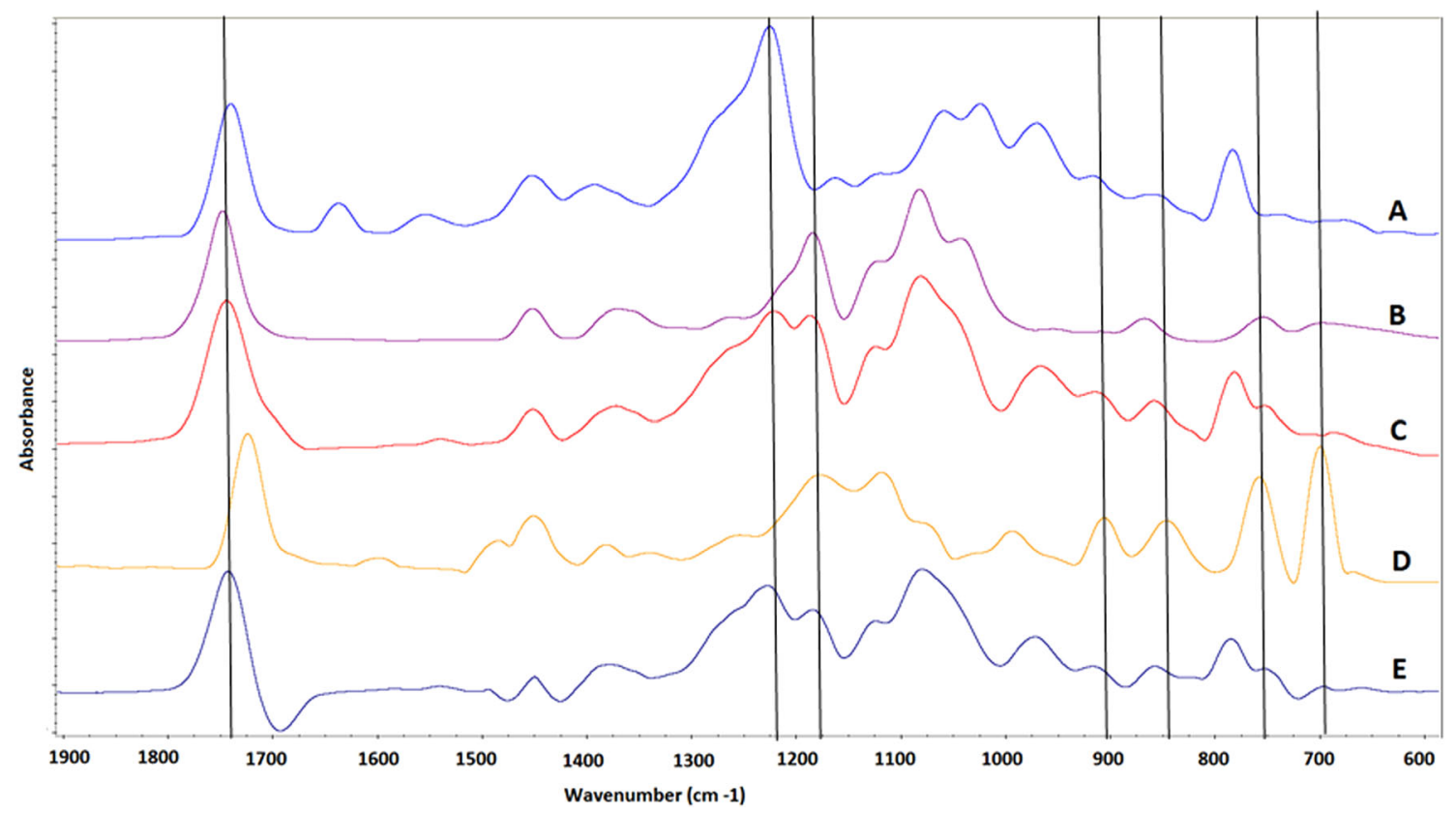

Fig. 5 FTIR spectra of $A$ PPC, $B$ PLA, $C$ PLA/PPC 40/60 blend film, $D$ Joncryl and $E$ PLA/PPC/Joncryl 40/60/0.5 blend film 
reaction of the epoxy functional groups of Joncryl with the carboxyl groups of the polymers.

Based on the FTIR spectra of the neat polymer and their blends, the disappearances and shifting of several specific stretching absorption peaks, it can be deduced that several appreciable interactions between the molecular chains of PLA/PPC blend and Joncryl took place during the melt processing. This shows Joncryl played a significant role in the interactions and reactions between PLA and PPC in the blend and increasing the compatibility of the blend, which also agrees with our result from mechanical property and morphology (SEM) studies.

\section{Water Vapor Permeability (WVP)}

The WVP values of neat PLA films, neat PPC films, PLA/ PPC blend films and PLA/PPC blend films with different amounts of Joncryl were measured to evaluate the water barrier performance. WVP with a unit of $\mathrm{g}^{*} \mathrm{mil} / 100 \mathrm{in}^{2}{ }^{2}$ day $\mathrm{mmHg}$ was calculated for every film samples following the equation:

$\mathrm{WVP}=\mathrm{WVTR} \times \mathrm{L} / \Delta \mathrm{P}$

where the WVTR is the transmission rate of water vapor through the films with a unit of $\mathrm{g} / \mathrm{m}^{2}$ day, $\mathrm{L}$ is the thickness of films with a unit of (mil). The $\Delta \mathrm{P}$ here is the saturated water vapor pressure at $37.82{ }^{\circ} \mathrm{C}$ with $100 \% \mathrm{RH}$, which is $49.17 \mathrm{mmHg}$. Figure 6 illustrates the WVP values of all six types of films. Neat PPC films exhibited the highest WVP value of $0.7202 \mathrm{~g} * \mathrm{mil} / 100 \mathrm{in}^{2}$ day $\mathrm{mmHg}$, indicating its poor barrier function to water vapor in comparison with the neat PLA and blends. Neat PLA films showed the lowest WVP value of $0.3688 \mathrm{~g}$ mil/100 in. ${ }^{2}$ day $\mathrm{mmHg}$. After blending PLA with PPC, the WVP of the PLA/PPC blend films showed a balanced value of $0.4358 \mathrm{~g} * \mathrm{mil} / 100 \mathrm{in.}^{2}$ day $\mathrm{mmHg}$ which falls in between the WVP value of neat PLA films and neat PPC films. Although the crystallinity was increased in the PLA/PPC blend mentioned in DSC analysis, the increased crystallinity did not help much in improving the water barrier performance. As for films with the addition of Joncryl, it can be noticed that with 0.2 phr addition of Joncryl into the blend, the WVP value has increased from 0.4358 to $0.5428 \mathrm{~g}$ *mil/ 100 in. $^{2}$ day $\mathrm{mmHg}$. This can be caused by the prevention effect on the crystallization of the blend induced by the addition of Joncryl, which led to lower crystallinity and less perfect crystal structure as mentioned in the DSC analysis. Hence, Joncryl induced the reduction of the impermeable crystal structure in the blend films, resulting in higher WVP value. When increasing the Joncryl content to $0.5 \mathrm{phr}$, WVP value showed increase from 0.5428 to $0.6292 \mathrm{~g} * \mathrm{mil} / 100 \mathrm{in}^{2}$ day $\mathrm{mmHg}$, which can be attributed to further decrease in the crystallinity. However, interestingly, a reduction of WVP values from 0.6292 (film with $0.5 \mathrm{phr}$ Joncryl) to $0.4854 \mathrm{~g} * \mathrm{mil} / 100 \mathrm{in}^{2}$ day $\mathrm{mmHg}$ was observed for the PLA/ PPC blend with $1 \mathrm{phr}$ Joncryl. This improvement of water barrier performance was considered to be caused by more formation of cross-linkings and branching structure among the polymer chains [15]. As such, the more intense distribution of the polymer chains and the less free volume fraction restrained the diffusion of the water vapor molecules $[29,30]$.

\section{Oxygen Permeability (OP)}

Oxygen permeability (OP) coefficients can be used to quantify the oxygen barrier properties. Oxygen permeability (OP) coefficients of the PLA/PPC blend film and films with various concentrations of Joncryl were determined to evaluate their oxygen barrier performance. OP
Fig. 6 Water vapor permeability of PPC films, PLA films and PLA/PPC blend films with and without Joncryl: $A$ PLA/PPC (40/60) blend films, $B$ PLA/PPC/Joncryl (40/60/ $0.2 \mathrm{phr}$ ) blend films, $C$ PLA/ PPC/Joncryl (40/60/0.5 phr) blend films, $D$ PLA/PPC/ Joncryl (40/60/1 phr) blend films, $E$ PLA films, $F$ PPC films

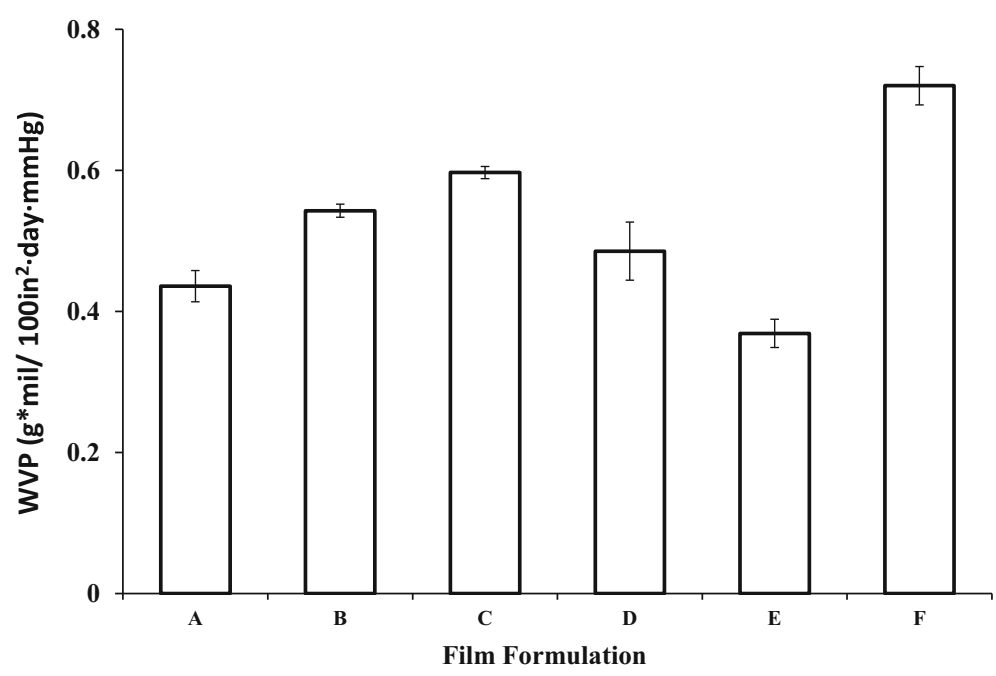


coefficients with a unit of cc*mil/100 in. ${ }^{2}$ atm day was obtained for each film sample using the following equation:

$\mathrm{OP}=\frac{O T R \times L}{\Delta P}$

where the OTR is the oxygen transmission rate of the sample, $\mathrm{L}$ is the thickness of films with a unit of (mil).The $\Delta P$ here is the partial pressure induced by the oxygen concentration gradient between the two sides of the sample. In our study, since $100 \%$ concentration of oxygen was applied in the experiment, $\Delta P$ is $1 \mathrm{~atm}(728 \mathrm{mmHg})$. The OP coefficients of PLA/PPC blend films with different concentration of Joncryl and neat PLA film were depicted in Fig. 7. With regard to the OP coefficient of neat PPC film, no valid results could be obtained. The oxygen transmission rate (OTR) of the neat PPC film in this study was too high (beyond the measuring limits of the equipment) to get a valid OTR value. This may be due to the inherent amorphous nature of PPC. The crystal structure of polymers is considered to be the impermeable barrier to gases and water vapor whereas the amorphous structure is responsible for providing the path for the permeants to diffuse through [30]. As such, its oxygen barrier can be very poor resulting in very high oxygen permeability coefficient.

Figure 7 shows that neat PLA film has a high OP coefficient of $54.21 \mathrm{cc}^{*} \mathrm{mil} / 100 \mathrm{in}^{2}{ }^{2}$ atm day. After blending PLA with PPC, the PLA/PPC 40/60 blend film exhibited much lower OP coefficient than the neat PLA film. Considering that PPC also has a high OP coefficient, the OP coefficient of the PLA/PPC blend did not follow the mixture rule. The combination of two relatively poor oxygen barrier polymers achieved a blend with much better oxygen barrier properties. This can be mainly ascribed to the higher crystallinity of PLA/PPC blend as compared to PLA, which was shown in the DSC study. It was observed that the incorporation of PPC can enhance the crystallization rate of PLA in the blend system, resulting in higher crystallinity than the crystallinity of neat PLA. Hence, the blend shows lower OP coefficient and better oxygen barrier property than both of the parent polymers.

As presented in Fig. 7, with increasing concentration of Joncryl in the blend film the OP coefficients of the film showed a downward trend. The PLA/PPC blend film with $0.2 \mathrm{phr}$ concentration of Joncryl presented the highest OP coefficient, demonstrating the worst oxygen barrier. The lower crystallinity caused by the addition of Joncryl could be the reason for this. However, the increase in the Joncryl concentration in the blend would bring about formation of more long chain branching and cross-linking structures. According to the study conducted by Salame et al. [31], higher cohesive energy between polymer chains led to lower free volume fraction resulting in better barrier property. Therefore, larger density of long chain branching and cross-linking structures reduced the free volume which promotes the oxygen barrier property. In this case, when the concentration of Joncryl increased from 0.2 to $0.5 \mathrm{phr}$ and $1 \mathrm{phr}$, the free volume fraction continuously reduced, resulting in decreased OP coefficient along with improved oxygen barrier compared to film with $0.2 \mathrm{phr}$. In summary, with small quantity of Joncryl $(<0.5 \mathrm{phr})$ the oxygen
Fig. 7 Oxygen permeability of PLA films and PLA/PPC blend films with and without Joncryl: $A$ PLA/PPC (40/60) blend films, $B$ PLA/PPC/Joncryl (40/60/ $0.2 \mathrm{phr}$ ) blend films, $C$ PLA/ PPC/Joncryl (40/60/0.5 phr) blend films, $D$ PLA/PPC/ Joncryl (40/60/1 phr) blend films, $E$ PLA films

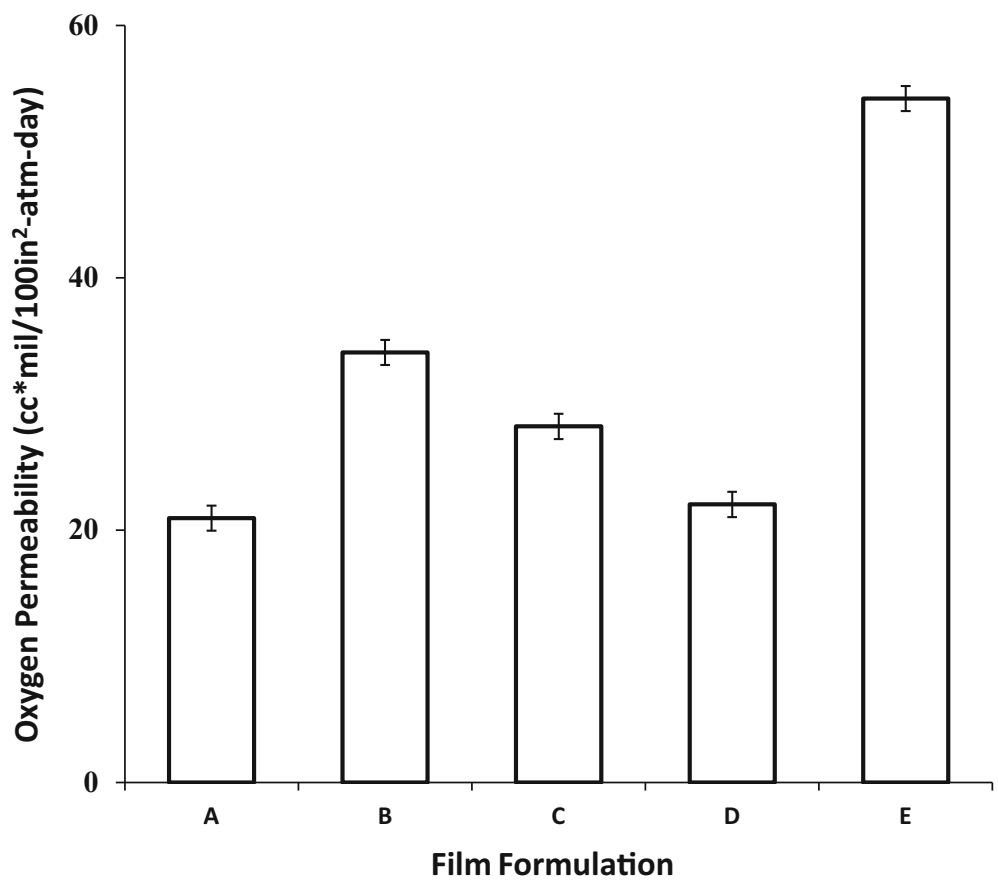


barrier of the PLA/PPC blend became poorer. On the other hand, the blend exhibited an enhanced trend in oxygen barrier property when the concentration of Joncryl was higher than $0.5 \mathrm{phr}$.

\section{Conclusion}

PLA/PPC blend films with different content of Joncry and without Joncryl were prepared; and their mechanical properties, thermal properties, morphology and possible chemical interactions between polymer matrix and Joncryl were investigated. With loading Joncryl into the blend system, the mechanical performance was largely enhanced with significant increment in elongation at break and slight increase in tensile strength. The films with $0.5 \%$ Joncryl loading exhibited the most optimal performance. The morphology and FTIR analysis revealed that the compatibility and interfacial adhesion between the polymers in the blend was significantly enhanced after loading Joncryl, which was caused by the formation of PLA-Joncryl-PPC copolymer through the reactions between Joncryl and PLA/ PPC component. Joncryl was observed to have an adverse effect on the crystallization of PLA in the PLA/PPC/Joncryl film, resulting in lower crystallinity of the compatibilized films. Interestingly, PPC was found to be able to accelerate the crystallization rate of PLA. As for the water vapor barrier properties of these blend films, the incorporation of PLA into the PPC system has comprehensively reduced the water vapor permeability, resulting in enhancing the water vapor barrier properties. When introducing the Joncryl into the blend system, the water vapor barrier properties was decreased, which can be corresponded to the adverse effect of Joncryl on the crystallization. However, further increase in Joncryl led to better water barrier properties as compared to films with lower Joncryl concentration. PLA/PPC blend film resulted in better oxygen barrier than both parent polymers due to the increased crystallinity of PLA. Lower Joncryl concentration compromised the oxygen barrier of the blend films as a result of hindered crystallization, whereas, the films with higher Joncryl concentration showed increasingly better oxygen barrier than films with lower Joncryl concentration. It could be concluded that the incorporation of Joncryl into the PLA/PPC blend films improved the overall performance of this PPC-PLA based films.

Acknowledgments The authors are thankful to the Ontario Ministry of Agriculture, Food and Rural Affairs (OMAFRA), Canada/ University of Guelph-Bioeconomy for Industrial Uses Research Program Theme (Project \# 200369); and the Natural Sciences and Engineering Research Council (NSERC), Canada - Discovery Grants (Project \# 400322) for the financial support to carry out this research work. The authors also would like to thank Dr. Loong-Tak Lim from
University of Guelph for his valuable suggestions during the preparation of this manuscript.

Open Access This article is distributed under the terms of the Creative Commons Attribution 4.0 International License (http://crea tivecommons.org/licenses/by/4.0/), which permits unrestricted use, distribution, and reproduction in any medium, provided you give appropriate credit to the original author(s) and the source, provide a link to the Creative Commons license, and indicate if changes were made.

\section{References}

1. Dong T, Yun X, Shi C et al (2014) Improved mechanical and barrier properties of PPC multilayer film through interlayer hydrogen bonding interaction. Polym Sci Ser A 56:830-836. doi:10.1134/S0965545X14060029

2. Inoue S, Koinuma H, Tsuruta T (1969) Copolymerization of carbon dioxide and epoxide. J Polym Sci Part B Polym Lett 7:287-292. doi:10.1002/pol.1969.110070408

3. Luinstra GA, Molnar F (2007) Poly(propylene carbonate), old $\mathrm{CO}_{2}$ copolymer with new attractiveness. Macromol Symp 259:203-209. doi:10.1002/masy.200751324

4. Xing C, Wang H, Hu Q et al (2013) Mechanical and thermal properties of eco-friendly poly(propylene carbonate)/cellulose acetate butyrate blends. Carbohydr Polym 92:1921-1927. doi:10. 1016/j.carbpol.2012.11.058

5. El-hadi AM (2014) The effect of additives interaction on the miscibility and crystal structure of two immiscible biodegradable polymers. Tech Sci Pap 24:9-16

6. Corre Y-M, Bruzaud S, Grohens Y (2013) Poly(3-hydroxybutyrate-co-3-hydroxyvalerate) and poly(propylene carbonate) blends: an efficient method to finely adjust properties of functional materials. Macromol Mater Eng 298:1176-1183. doi:10. 1002/mame.201200345

7. Varghese JK, Na SJ, Park JH et al (2010) Thermal and weathering degradation of poly(propylene carbonate). Polym Degrad Stab 95:1039-1044. doi:10.1016/j.polymdegradstab.2010.03.006

8. Yoo SJ, Lee SH, Jeon M et al (2013) Effects of compatibilizers on the mechanical, morphological, and thermal properties of poly(propylene carbonate)/poly(methyl methacrylate) blends. Macromol Res 21:1182-1187. doi:10.1007/s13233-013-1159-6

9. Garlotta D (2001) A literature review of poly (lactic acid). J Polym Environ 9:63-84. doi:10.1023/A:1020200822435

10. Nagarajan V, Zhang K, Misra M, Mohanty AK (2015) Overcoming the fundamental challenges in improving the impact strength and crystallinity of PLA biocomposites: influence of nucleating agent and mold temperature. ACS Appl Mater Interfaces 7:11203-11214. doi:10.1021/acsami.5b01145

11. Yao M, Deng H, Mai F et al (2011) Modification of poly(lactic acid)/poly(propylene carbonate) blends through melt compounding with maleic anhydride. Express Polym Lett 5:937-949. doi:10.3144/expresspolymlett.2011.92

12. Ma X, Jiugao Y, Wang N (2006) Compatibility characterization of poly(lactic acid)/poly(propylene carbonate) blends. J Polym Sci Part B Polym Phys 44:94-101. doi:10.1002/polb.20669

13. Di Lorenzo ML, Ovyn R, Malinconico M et al (2015) Peculiar crystallization kinetics of biodegradable poly(lactic acid)/ poly(propylene carbonate) blends. Polym Eng Sci. doi:10.1002/ pen. 24058

14. Henan Tianguan Enterprise Group Co. Ltd. Data Sheet of Poly(propylene Carbonate). http://www.tgnbm.com/cpzx/ppc/

15. Arruda LC, Magaton M, Suman Bretas RE, Ueki MM (2015) Influence of chain extender on mechanical, thermal and 
morphological properties of blown films of PLA/PBAT blends. Polym Test 43:27-37. doi:10.1016/j.polymertesting.2015.02.005

16. Wang Y, Fu C, Luo Y et al (2010) Melt synthesis and characterization of poly(L-lactic acid) chain linked by multifunctional epoxy compound. J Wuhan Univ Technol Mater Sci Ed 25:774-779. doi:10.1007/s11595-010-0090-3

17. Khonakdar HA, Morshedian J, Wagenknecht U, Jafari SH (2003) An investigation of chemical crosslinking effect on properties of high-density polyethylene. Polymer (Guildf) 44:4301-4309. doi:10.1016/S0032-3861(03)00363-X

18. Rathi S, Coughlin E, Hsu S et al (2014) Maintaining structural stability of poly(lactic acid): effects of multifunctional epoxy based reactive oligomers. Polymers (Basel) 6:1232-1250. doi:10. 3390/polym6041232

19. Al-Itry R, Lamnawar K, Maazouz A (2012) Improvement of thermal stability, rheological and mechanical properties of PLA, PBAT and their blends by reactive extrusion with functionalized epoxy. Polym Degrad Stab 97:1898-1914. doi:10.1016/j.poly mdegradstab.2012.06.028

20. Zhai W, Ko Y, Zhu W et al (2009) A study of the crystallization, melting, and foaming behaviors of polylactic acid in compressed $\mathrm{CO}_{2}$. Int J Mol Sci 10:5381-5397. doi:10.3390/ijms10125381

21. Jaszkiewicz A, Bledzki AK, van der Meer R et al (2014) How does a chain-extended polylactide behave? A comprehensive analysis of the material, structural and mechanical properties. Polym Bull 71:1675-1690. doi:10.1007/s00289-014-1148-8

22. Yasuniwa M, Tsubakihara S, Sugimoto Y, Nakafuku C (2004) Thermal analysis of the double-melting behavior of poly(L-lactic acid). J Polym Sci Part B Polym Phys 42:25-32. doi:10.1002/ polb. 10674

23. Li XH, Meng YZ, Zhu Q, Tjong SC (2003) Thermal decomposition characteristics of poly(propylene carbonate) using TG/IR and Py-GC/MS techniques. Polym Degrad Stab 81:157-165. doi:10.1016/S0141-3910(03)00085-5

24. Kuo SW, Huang CF, Chang FC (2001) Study of hydrogenbonding strength in poly( $\varepsilon$-caprolactone) blends by DSC and FTIR. J Polym Sci Part B Polym Phys 39:1348-1359. doi:10. 1002/polb.1107

25. Fei B, Chen C, Peng S et al (2004) FTIR study of poly(propylene carbonate)/bisphenol A blends. Polym Int 53:2092-2098. doi:10. 1002/pi.1633

26. Sengupta R, Chakraborty S, Bandyopadhyay S et al (2007) A short review on rubber/clay nanocomposites with emphasis on mechanical properties. Engineering 47:21-25. doi:10.1002/pen

27. Qin Y, Chen L, Wang X et al (2011) Enhanced mechanical performance of poly(propylene carbonate) via hydrogen bonding interaction with o-lauroyl chitosan. Carbohydr Polym 84:329-334. doi:10.1016/j.carbpol.2010.11.045

28. Mekonnen T, Mussone P, El-Thaher N et al (2013) Thermosetting proteinaceous plastics from hydrolyzed specified risk material. Macromol Mater Eng 298:1294-1303. doi:10.1002/mame. 201200429

29. Yampolskii YP, Korikov AP, Shantarovich VP et al (2001) Gas permeability and free volume of highly branched substituted acetylene polymers. Macromolecules 34:1788-1796. doi:10. $1021 / \mathrm{ma} 000628 \mathrm{u}$

30. Lee WM (1980) Selection of barrier materials from molecular structure. Polym Eng Sci 20:65-69. doi:10.1002/pen.760200111

31. Salame M (1986) Prediction of gas barrier properties of high polymers. Polym Eng Sci 26:1543-1546. doi:10.1002/pen. 760262203 